\title{
Development of a Cost-effective Biomechanical System for the Assessment of Kinematic and Kinetic Parameters in Soccer Players During a Lower Limb Pointing Task
}

MARCELO GUIMARAES SILVA ( $\nabla$ marceloguimas@bol.com.br)

UNESP: Universidade Estadual Paulista Julio de Mesquita Filho https://orcid.org/0000-0001-5698-262X Henrique Martins Rocha

UERJ

Cathrine Katsigianni

None

\section{Research Article}

Keywords: Cost-effective combined system, kinematic parameters, kinetic parameters, kicking accuracy

Posted Date: October 28th, 2021

DOl: https://doi.org/10.21203/rs.3.rs-992204/v1

License: (c) (i) This work is licensed under a Creative Commons Attribution 4.0 International License. Read Full License 


\section{Abstract}

\section{Purpose}

The main aim of the present study was to describe the development of a non-commercial biomechanical system designed for the simultaneous measurement of kinematic and kinetic parameters during a lower limb pointing task. The task was performed by two groups of soccer players ( 10 novices and 10 experts, aged 16-19 years) and the differences between the two groups, in terms of these parameters, were also assessed.

Methods

The calibration procedure of the combined system is presented in this paper. The system measured the Centre of Pressure (CoP) and body Center of Mass (CoM) displacements, kicking duration and the acceleration of the kicking leg.

Results

The margin of error found for kinematic and kinetic calibration was less than $1 \%$. Furthermore, the expert players presented decreased CoP and CoM displacements and kicking duration and acceleration of the kicking leg compared to the novices.

Conclusion

The combined system provides an effective method for the simultaneous measurement of kinematic and kinetic parameters associated with kicking and may contribute to the development of intervention studies for the improvement of balance and kicking performance in sports.

\section{Introduction}

A lower limb pointing task is mainly related to kicking accuracy, which entails delivering the ball with precision over a desired distance to an intended target [1, 2]; precision is achieved by reducing velocity during an accurate kick, which allows players to minimise errors. Reducing velocity results in longer duration of the shooting phase [3]. Duration refers to the time a player takes to carry out the kicking movement, from the moment the supporting leg is in contact with the ground to initial ball impact $[3,4,5]$.

Maintaining postural stability-i.e. keeping the body's centre of mass (CoM) over the base of support by moving the centre of pressure (CoP) of the ground reaction forces (GRF) beneath the feet- during an accurate kick also allows the players to minimise errors and attain kicking accuracy $[6,7,8]$. To maintain postural stability throughout the phases of the kick, players must minimise CoM and CoP displacements and velocities $[2,8,9]$.

Several methods have been developed to measure the above kinematic and kinetic parameters related to the soccer kick. Velocities and accelerations have been measured using two- and three- dimensional 
videography $[2,10,11,12,13,14]$ and accelerometry $[13,14]$. Three-dimensional motion capture can measure kinematic parameters more accurately; however, this method requires several cameras and markers, which is time consuming and can have other problems: for example, the employment of smoothing filters makes it difficult to distinguish between true deceleration due to the impact with the ball and false acceleration signals produced by the noise in the data $[15,16,17,18,19]$. Accelerometry, on the other hand, measures human movement through sensors directly attached to the body part which is measured without requiring any filters $[13,14,19]$.

External forces (GRF, CoP) can be measured through a force platform which provides electrical signals relative to the applied forces $[20,21]$. Measuring these forces simultaneously with kinematic data through combined systems can provide a time-effective and comprehensive method [21, 22, 23]. A study by [22], used a combined system consisting of a force platform, an accelerometer and an electromechanical device to simultaneously measure kinetic and kinematic variables during a controlled kick by comparing the signals from the three devices.

To our knowledge, non-commercial combined systems are scarce. We, therefore present a combined system that consists of three devices for the simultaneous measurement of kinematic and kinetic variables related to a lower limb kicking task. Furthermore, since the players' level of expertise has been shown to influence these parameters $[8,23,24,25,26]$, a secondary purpose of the present investigation was to use the system to measure the differences between expert and novice players, in terms of CoP and CoM displacement, kicking accuracy and duration during the performance of the kicking task.

\section{Materials And Methods}

Description regarding of the devices and kinematic and kinetic apparatus and calibration procedures can be found in the supplementary material.

\section{Experimental study}

An experimental study consisting of a lower limb pointing task was performed by twenty male ( 10 experienced and 10 novice) soccer players (mean age $18.35 \pm 0.58$ years old, weight $72.8 \pm 5.69 \mathrm{~kg}$, and height $178.36 \pm 5.74 \mathrm{~cm}$ ). None of the participants reported any orthopaedic condition or musculoskeletal disorder during the six months prior to the data collection. The experienced players had to participate in regional level championships (U- routine of three 1-hr training sessions per week.

The participants' task was to kick a ball at their own pace with the instep of their right foot (declared as the participants' preferred foot) as accurately as possible, 20), keep a routine of four 1.5-hr training sessions per week, and have at least five years playing experience. The novice players were amateur college students with a minimum of three years playing experience and had to keep a toward a target $(2.0 \mathrm{~m} \times 2.0$ $\mathrm{m}$ ) positioned at a ground level, $6.0 \mathrm{~m}$ away from the participants. The right foot was placed out of the platform, close to the ball, while the left foot remained on the force platform throughout the task. Once stabilised through a minimal sway for $3 \mathrm{~s}$, the participants performed the accurate kick, and then returned 
to the starting position without stopping the movement or touching the floor with their right foot. If a participant stopped the movement or touched the floor the trial was considered invalid and had to be repeated. Each participant performed eight kicks with one min rest interval between kicks.

The three- dimensional coordinates were recorded through two digital cameras which were turned on after the participants had positioned themselves on the FP and turned off after the performance of the kick (Figure 1, supplementary material). These coordinates were expressed as a right-handed orthogonal reference frame fixed on the ground. The following sign convention was adopted: $x$ for the AP axis, horizontal and pointed to the centre of the target (positive forward and negative backward), $y$ for the ML axis, perpendicular to $x$ (positive to the right and negative to the left) and $z$ for the craniocaudal axis (positive upward and negative downward).

All signals were captured by an HBM Spider8 conditioner with a CATMAN software, sampled at $100 \mathrm{~Hz}$ (HBM Spider8, with 16-bit resolution and 16 channels A/D converter). After the kicks had been recorded, the files were archived and sequenced from 1 to 8 (first to last kick). The video of each kick was divided into frames with one image every $0.033 \mathrm{~s}(30 \mathrm{~Hz})$. To obtain the CoM displacement for each phase of the kick the program "am3DKick" (UNESP - Biomechanics Laboratory) was used. Fourty frames were obtained from each digital camera marking the anthropometric points of the images (total of 80 frames). The data were saved and archived for further analysis.

The FP signals were sampled at $100 \mathrm{~Hz}$ (HBM Spider8, with 16-bit resolution and 16 channels A/D converter) and filtered through a zero lag second-order pass Butterworth filter (10 Hz low-pass cut-off frequency with a dual pass to remove phase shift.

The accelerometer was synchronised with the force platform through a resampling method of two time series objects using a common time vector in Matlab. The data from both time series were collected through a conditioner of signals (Spider 8) and interpreted by the CATMAN software. The trials were also viewed off-line on a monitor screen and temporally synchronised, according to the first visible deflection of the right ankle kinematics signal, defined as the instant the right foot was raised off the ground. This time was considered as "time zero" (T0) for all subsequent analyses.

\section{Dependent variables}

The dependent variables associated the lower limb precision task, included kicking analysis and calculation of mean AP and ML amplitude $(\mathrm{mm})$ and speed $(\mathrm{mm} / \mathrm{s})$ of CoP and CoM displacement. Three dependent variables described the kicking movement: kicking accuracy, duration, and right foot acceleration. Kicking accuracy was established as the sum of the different scores across trials, as follows: 1) the ball missed the target, 2) the ball reached the outer target zone 3) the ball reached the central target zone. The higher the score, the higher was the kicking accuracy.

The duration of the accurate kick was examined in connection with the backswing and shooting phases; the latter corresponds to the forward and impact phases presented by other authors [2, 27]: 1) The backswing phase: the swing of the kicking leg in preparation for the downward motion towards the ball 
which started with the raising of the right ankle until the maximal backward position of the limb was reached 2) the shooting phase: kicking towards the target which started from the maximal backward position until the right foot was in contact with the ball toward the target $[26,27]$. The sum of those phases represented the total duration of the kick. The foot contact with the ball was determined directly through the accelerometer signal, defined as the time of peak deceleration during the shooting phase.

Four dependent variables mean mediolateral $(\mathrm{ML})$ and anteroposterior $(\mathrm{AP})$ amplitude $(\mathrm{mm})$ and speed $\left(\mathrm{mm} . \mathrm{s}^{-1}\right)$ of CoP displacements, described the participants' postural behaviour during the kicking task for the backswing and shooting phase. The amplitude of CoP displacements indicated the mean deviation of $\mathrm{CoP}$ in the ML and AP axes. The mean speed of CoP displacements is the sum of the displacement scalars divided by the sampling time, i.e., the duration of each movement phase. It represents the amount of activity required to maintain stability and provides a more functional measure of postural control $[28,29]$.

The amplitude and speed of CoM displacements in the ML and AP axes were obtained through the kinematics method that estimates CoM displacements through the trajectory of the body segments in function of time [17]. To calculate the CoM displacement in the ML and AP axes, a three-dimensional reconstruction of the markers' kinematics data combined with anthropometric measurements was performed through off-line data processing techniques from Winter's model, in which the mass of each segment is given as a function of the total mass and the CoM, and the radius of rotation of these segments is provided as a function of their lengths [30].

To allow the kinematic identification of each anatomical segment and ensure reliable between-participant data, $15 \mathrm{~mm}$ styrofoam hemi-spheres were attached to the 16 anatomical landmarks in all the participants: left and right ear, acromion, anterior superior iliac spine, knee, lateral malleolus, fifth metatarsal, elbow and wrist joints [30].

\section{Statistical analysis}

Kicking accuracy was submitted to a one-way analysis of variance (ANOVA). Kicking time, foot acceleration, CoP and CoM dependent variables were submitted to 2 conditions (experienced vs. novices) $\mathrm{x}$ 2 movement phases (backswing vs. shooting) ANOVAs with repeated measures for both factors. The level of significance was set at $p<.05$. Whenever the ANOVA showed a significant effect, a Tukey's HSD post hoc test was performed for multiple comparisons. All statistical analyses were carried out using SPSS 10.0 software (SPSS Inc., Chicago, IL, USA).

\section{Results}

\section{Calibration}

\section{Kinematic apparatus}

Spatial calibration results 
The equations used to reconstruct the images can be found in the supplementary material $(p p 5,6)$. The margin of error found for calibration through reconstruction of the three-dimensional image was less than $1 \%$.

Accelerometer calibration results

Results measured from the accelerometer signal showed that the maximum voltage indicated by the oscilloscope was $+2.8 \mathrm{~V}$, the medium voltage $+2.64 \mathrm{~V}$ and the minimum voltage $+2.48 \mathrm{~V}$, corresponding to $+3 \mathrm{~g},+1 \mathrm{~g}$ and $-1 \mathrm{~g}$ respectively.

\section{Kinetic apparatus}

Force platform calibration results

The sum of the outputs from the four load cells presented a correlation coefficient $R^{2}=1$ in the load range of 0 to $900 \mathrm{~N}$, equivalent to the total capacity that each load cell can support.

The load cells presented a linearity and hysteresis with error below $0.25 \%$ of the vertical and $0.31 \%$ of the horizontal for a full scale (900 N) (Figure $4 \mathrm{a}, \mathrm{b}$ ).

The hysteresis and linearity presented the following results: hysteresis $(\mathrm{Mx}=4.91 \%, \mathrm{My}=7.16 \%, \mathrm{Mz}=$ $6.04 \%)$; linearity $(\mathrm{My}=0.9872, \mathrm{Z}=0.9973, \mathrm{Mx}=0.9692)$. The force platform presented a resolution of $0.003685 \mathrm{Nm}$ in $\mathrm{Mx}, 0.004327 \mathrm{Nm}$ in My and $0.035403 \mathrm{~N}$ in the $Z$ axis. To measure the accuracy and precision of the CoP (reproducibility), the test of distributed load was applied, which is the closest to reality regarding the stabilometric platform. Table 2 shows the actual values of CoPpredicted and CoPmeasured, demonstrating the accuracy of the force platform. The error was calculated by subtracting the CoPmeasured from the CoPpredicted.

The response to the thrust applied on the platform in the dynamic experimental analysis, showed different peaks of frequency in the vibration mode analysis, progressively increasing between the first and the fifth vibration mode analysed: (1) $110 \mathrm{~Hz}$; (2) $176 \mathrm{~Hz}$; (3) $203 \mathrm{~Hz}$; (4) $259 \mathrm{~Hz}$; (5) $267 \mathrm{~Hz}$. It was determined that the natural vibration frequency of this platform was not less than $110 \mathrm{~Hz}$.

\section{Experimental study results}

The kicking accuracy was lower in the novices than in the experienced players $[F(1,38)=4.17, p=.027$, $31.8 \pm 7.24$ vs. $49.58 \pm 10.09]$. The total duration of the kick was longer in the novices than in the experienced players $[F(1,38)=3.27, p=.042,1.19 \mathrm{~s}$ vs. $.83 \mathrm{~s}+36 \mathrm{~ms}]$. The time and foot acceleration results are shown in Table 3.

The post hoc revealed that the duration of the backswing phase was longer in the novices than it was in the experienced players $(p<.001)$ whereas the duration of the shooting phase was similar between the two groups. The foot acceleration of the backswing phase was slower in the novices than in the experienced players $(p<.05)$ whereas the foot acceleration of the shooting phase was similar between the two groups. 
No significant effect was observed when the kicking duration was analysed from T0 until the time that the foot was in contact with the ball toward the target $(p>.05)$. The results for the mean amplitude and speed of CoP and CoM displacement are shown in Table 4.

The analysis of the mean CoP amplitude showed a main effect of condition, with a larger mean amplitude for the novices than for the experienced players. The main effect of phase and the interaction of Condition $x$ Phase for the AP mean amplitude were not significant. The analysis of the mean CoP speed in the AP axis showed a main effect of condition, suggesting a faster CoP speed in the novices than in the experienced players. No main effect of phase and no interaction of Condition $\times$ Phase was observed. In the ML axis, no significant effect was observed.

The analysis of the AP mean amplitude of CoM displacement showed a main effect of condition with a larger mean amplitude of displacement for the novices than for the experienced players. The main effect of phase and the interaction of Condition $x$ Phase were not significant. In the ML axis no significant effect was observed. The analysis of mean CoM speed in the AP axis showed a main effect of condition, suggesting a faster CoM speed in the novices than in the experienced players. No significant main effect of phase and no significant interaction of Condition $\times$ Phase was observed in the analyses of the amplitude of the CoP and CoM ${ }_{\text {AP }}$ displacements, and AP CoP speed. No significant effect of phase, in terms of the CoP and $\mathrm{CoM}_{\mathrm{ML}}$ amplitude, was observed.

\section{Discussion}

The kinematic calibration through reconstruction of the 3D image presented a margin of error less than $1 \%$, in accordance with previous studies [31]. Therefore, the three-dimensional system developed in the present study captured the participants' movement during the kicking task, in different planes/axes. The calibration results showed that the sensor presented a level of oscillation $(\mathrm{g})$ range varying between -1 to $+3 \mathrm{~g}$, confirming that this device responded adequately to the acceleration to which it was submitted [32], which is in accordance with previous studies [22, 31, 32, 33].

Furthermore, the platform presented an adequate connectivity, linearity and hysteresis as well as a satisfactory resolution and sensitivity of curves, combined with a structural rigidity and low weight. The errors in the CoP location were less than $1 \mathrm{~mm}$, in accordance with previous studies [21, 34].

Contrary to previous studies [34,35], the CoP measurement error found during the distributed load test was greater than the error observed during the application of the centralised load. This could have been caused by an uneven load distribution on the plate not well transferred to the four load cells or imperfections on the plate $[22,35]$. Though this characteristic appears to be negative, it showed that a system designed in this manner can reduce the hysteresis effects [21].

In addition, the system was used to measure the kinematic and kinetic parameters of the kicking task in expert and novice players since it has been shown that long term training contributes to high level of coordinated movement and balance $[2,8,12,35]$. The novices presented greater right foot acceleration 
than the expert players during the kicking action, which resulted in less accuracy $[33,37,38]$. Expert players in $[39,40]$ achieved the most accurate kicks when they prioritised precision over velocity.

Moreover, the novice players spent more time to perform the backswing movement whereas the duration of the shooting phase was similar between the groups [41, 42]. Novice players need to focus on the components of the performed task, resulting in delays in performing the task $[43,44,45,46]$. In the present study novices spent longer on maintaining stability and controlling the movement of their kicking leg during the backswing phase compared to experts; therefore, this phase lasted longer for the novices.

In addition, CoP and CoM analyses were performed in the AP and $\mathrm{ML}$ axes since postural balance during the kick depends mainly on the lateral and frontal oscillations of the supporting foot [20]. Novice players presented greater amplitude and speed of CoP displacement values and, therefore, greater postural instability than expert players. There was greater CoP variability in the AP than in the ML axis, which was more consistent with the backswing phase $[27,41,47,48]$. Previous studies investigating groups of amateur and elite soccer players, found greater variability in the ML axis and a reduced AP CoP displacement in amateur players $[49,50]$, which apparently contradicts our results.

Novices presented a greater amplitude and speed of CoM displacement than expert players. A significant forward CoM displacement during the backswing phase [41] enabled the novices to maintain stability [41, 51]. Amateur players in the study by [52] also presented a significant forward CoM displacement throughout the phases of an instep kick.

\section{Conclusion}

The present study aimed at developing a cost-effective combined system for the simultaneous measurement of kinematic and kinetic parameters during a lower limb pointing task performed by expert and novice players. The results of the calibration and experimental study indicate that the combined system presents a comprehensive method for the assessment of dynamic postural stability and kicking performance.

To ensure generalisability of findings future research should include athletes of different ages, both male and female.

\section{Declarations}

\section{Declaration of conflicting interests}

The author(s) declared no potential conflicts of interest with respect to the research, authorship, and/or publication of this article.

\section{Funding}

The authors did not receive support from any organization for the submitted work. 


\section{Ethics Approval}

All procedures performed in studies involving human participants were in accordance with the ethical standards of the institutional and/or national research committee and with the 1964 Helsinki Declaration and its later amendments or comparable ethical standards. The study was approved by the Local Ethics Committee of the UNITAU (No. 523/08).

\section{Consent to participate}

Informed consent was obtained from all individual participants included in the study.

\section{Consent to publish}

Sample statements if identifying information about participants is available in the article.

\section{Authors' contribution}

All authors listed have made a substantial, direct, and intellectual contribution to the work, and approved it for publication.

\section{References}

[1] Asami, T., \& Nolte, V. (1983). Analysis of powerful ball kicking. In: H. Matsui \& K. Kobayashi. (Eds.), Biomechanics VIII-B (pp. 695-700). Champaign, IL: Human Kinetics.

[2] Levanon, J., \& Dapena, J. (1998). Comparison of the kinematics of the full instep and pass kicks in soccer. Medicine \& Science in Sports \& Exercise, 30, 917-929. https://doi:10.1097/00005768-1998060000022

[3] Teixeira, L. A. (1999). Kinematics of kicking as a function of different sources of constraint on accuracy. Perceptual and Motor Skills, 88(3 Pt 1), 785-789. https://doi:10.2466/PMS.88.3.785-789

[4] Barfield, W. (1995). Effects of selected kinematic and kinetic variables on instep kicking with dominant and non -dominant limbs. Journal of Human Movement Studies, 29, 251-272.

[5] Katis, A., Giannadakis, E., Kannas, T., Amiridis, I., \& Kellis, E. (2004). Mechanisms that influence accuracy of the soccer kick. Journal of Electromyography and Kinesiology, 2004; 23:125131. https://doi:10.1016/j.jelekin.2012.08.020.

[6] Kirshenbaum, N., Riach, C. L., \& Starkes, J. L. (2001) Non-linear development of postural control and strategy use in young children: A longitudinal study. Experimental Brain Research, 140: 420431. https://doi:10.1007/s002210100835.

[7] Walsh, G. S., Low, D. C., \& Arkesteijn, M. (2020). Stable and unstable load carriage effects on the postural control of older adults. Journal of Applied Biomechanics, 5:1-8. https://doi:10.1123/jab.2019- 
0366.

[8] Chew-Bullock, T. S. Y., Anderson, D. I., Hamel, K. A., Gorelick, M. L., Wallace, S. A., \& Sidaway, B. (2012). Kicking performance in relation to balance ability over the supporting leg. Journal of Sports Sciences, 31:1615-1623. https://dx.doi.org/10.1016/j.hmov.2012.07.001.

[9] Ball, K. (2011). Centre of mass motion during the punt kick. In: Vilas-Boas, Machado, Kim, Veloso (Eds.), Biomechanics in Sports 29. Portuguese Journal of Sport Sciences (11 Suppl. 2) (pp. 44-48).

[10] Barfield, W. R., Kirkendall, D. T., \& Yu, B. (2002). Kinematic instep kicking differences between elite female and male soccer players. Journal of Sports Sciences, 72-79. PMCID: PMC3967432.

[11] Dörge, H. C., Andersen, T. B., Sørensen, H., \& Simonsen, E. B. (2002). Biomechanical differences in soccer kicking with the preferred and non- preferred leg. Journal of Sports Sciences, 20(4), 293299. https://dx.doi.org/10.1080/026404102753576062

[12] Nunome, H., Ikegami, Y., Kozakai, R., Apriantono, T., \& Sano S. (2006 a). Segmental dynamics of soccer instep kicking with the preferred and non-preferred leg.

Journal of Human Kinetics, 24(5), 529-541. https://doi:10.1080/02640410500298024.

[13] Godfrey, A., Meagher, D. J., Godfrey, R., \& Olaighin, G. (2009). Direct measurement of human movement by accelerometry. Medical Engineering \& Physics, 30, 1364-1386.

[14] Mathie, M., Coster, A., Lovell, N., \& Celler, B. (2004). Accelerometry: Providing an integrated practical method for long-term ambulatory monitoring of human movement.

Physiological Measurement, 25, R1-R20.

[15] Meamarbashi, A., Reza, A., \& Hossaini, S. R. A. (2010). Application of Novel Inertial Technique to Compare the Kinematics and Kinetics of the Legs in the Soccer Instep Kick.

Journal of Human Kinetics, 23, 3-12.

[16] Nunome, H., Lake, M., Georgakis, A., \& Stergioulas L. K. (2006 b). Impact phase kinematics of instep kicking in soccer. Journal of Sports Sciences, 24, 11-22.

[17] Mapelli, A., Zago, M., Fusini, L., Galante, D., Colombo, A., \& Sforza, C. (2014). Validation of a protocol for the estimation of three-dimensional body center of mass kinematics in sport. Gait \& Posture, 39, 460465. https://doi:10.1016/j.gaitpost.2013.08.025.

[18] Corrazza, S., Gambaretto, E., Ferrigno, G., \& Andriacchi, T. (2010). Markerless motion capture through visual hull, articulated ICP and subject specific model generation.

International Journal of Computer Vision, 87, 156-169. 
[19] Shan, G., \& Westerhof, P. (2005). Full-body kinematic characteristics of the maximal instep soccer kick by male soccer players and parameters related to kick quality. Sports Biomechanics, 4(1), 59-

72. https://doi:10.1080/14763140508522852.

[20] Barela, A. M. F., \& Duarte, M. (2011). Utilização da plataforma de força para aquisição de dados cinéticos durante a marcha humana. Journal of Motor Behavior, 6(1), 56-61.

[21] Silva, M. G., Moreira, P. V. S., \& Rocha, H. M. (2017). Development of a low-cost force platform for biomechanical parameters analysis. Research on Biomedical Engineering, 33, 259268. https://dx.doi.org/10.1590/2446-4740.01217.

[22] Alves, B. M. O., Da Silva, R. A., Rosa, L. M., Mesquita, T. R., De Oliveira, P. R., Burigo, R., \& Amorim, C. F. (2018). Postural control analysis during a standardized kick task in soccer athletes. Revista Brasileira de Medicina do Esporte, 24(2), 89-96. https://doi.org/10.1590/1517-869220182402181470

[23] Era, P., Konttinen, N., Mehto, P., Saarela, P., \& Lyytinen, H. (1996). Postural stability and skilled performance - A study on top level and naïve rifle shooters. Journal of Applied Biomechanics, 29(3), 301306. https://doi:10.1016/0021-9290(95)00066-6.

[24] Rodano, R., \& Tavana, R. (1991). Three-dimensional analysis of instep kick in professional soccer players. In: Reilly T, Clarys J, Stibbe A. (Eds.), Science and Football (pp.357-361). London: E \& FN Spon.

[25] Kawamoto R., Miyagi, O., Ohashi, J., Fukashiro, S. (2007). Kinetic comparison of a side-foot soccer kick between experienced and inexperienced players. Sports Biomechanics, 6:187-

198. https://doi:10.1080/14763140701324166.

[26] Nunome, H., Asai, T., Ikegami, Y., \& Sakurai, S. (2002). Three-dimensional kinetic analysis of side-foot and instep soccer kicks. Medicine \& Science in Sports \& Exercise, 34(12), 2028-

2036. https://doi:10.1097/00005768-200212000-00025.

[27] Kellis, E., \& Katis, A. (2007). Biomechanical characteristics and determinants of instep soccer kick. Journal of Sports Science and Medicine, 6(2), 154-165. Retrieved from http://www.jssm.org.

[28] Geurts, A. C., Nienhuis, B., Mulder, T. W. (1993). Intra subject variability of selected force-platform parameters in the quantification of postural control. Archives of Physical Medicine and Rehabilitation, 74, 1144-1150.

[29] Vuillerme, N., Forestier, N., \& Nougier, V. (2002). Attentional demands and postural sway: the effect of the calf muscles fatigue. Medicine \& Science in Sports \& Exercise, 34(12), 1907-

1912. https://doi:10.1097/00005768-200212000-00008.

[30] Winter, D. A. (1990). Biomechanics and motor control of human movement. New York, NY: Wiley. 
[31] Mercer, J. A., Bates, B. T., Dufek, J. S., \& Hreljac, A. (2003). Characteristics of shock attenuation during fatigued running. Journal of Sports Sciences, 21, 911-919.

https://doi.org/10.1080/0264041031000140383.

[32] Wesson, J. (2002). The Science of Soccer, Taylor \& Francis Group, New York, United States of America.

[33] Katis, A., Giannadakis, E., Kannas, T., Amiridis, I., Kellis, E., Lees, A. (2013). Mechanisms that influence accuracy of the soccer kick. Journal of Electromyography and Kinesiology, 23(1), 12531. https://doi.org/10.1016/j.jelekin.2012.08.020.

[34] Cedraro. A., Cappello, A., \& Chiari, L. (2009). A portable system for in-situ re-calibration of force platforms: experimental validation. Gait \& Posture, 29(3), 449453. https://doi:10.1016/j.gaitpost.2008.11.004.

[35] Rana, N. (2009). Application of force sensing resistor (FSR) in design of pressure scanning system for plantar pressure measurement. Proceedings of the 2nd International Conference on Computer and Electrical Engineering, Dubai, UAE (pp. 678-685). https://doi:10.1109/ICCEE.2009.234.

[36] Casey, B. J., Galvan, A., Hare, T. A. (2005 a). Changes in cerebral functional organization during cognitive development. Current Opinion in Neurobiology, 15(2):239-244.

[37] Davids, K., Lees, A., Burwitz, L. (2000). Understanding and measuring coordination and control in kicking skills in soccer: Implications for talent identification and skill acquisition.

Journal of Sports Sciences, 18(9), 703-714. https://doi:10.1080/02640410050120087.

[38] Hodges, N. J., Hayes, S., Horn, R. R., Williams, A. M. (2005). Changes in coordination, control, and outcome as a result of extended practice with the non-dominant foot on a soccer skill. Ergonomics, 48, 1672-1685. https://doi:10.1080/00140130500101312.

[39] Ižovská, J., Maly, T., \& Zahàlka, F. (2016). Relationship between speed and accuracy of instep soccer kick. Journal of Physical Education and Sport, 16(2), 459-464. https://doi:10.7752/jpes.2016.02070.

[40] Van den Tillaar, R., \& Ulvik, A. (2014). Influence of instruction on velocity and accuracy in soccer kicking of experienced soccer players. Journal of Motor Behavior, 46(5), 287-

291. https://doi:10.1080/00222895.2014.898609.

[41] Andersen, T. B., \& Dorge, H. C. (2011). The influence of speed of approach and accuracy constraint on the maximal speed of the ball in soccer kicking. Scandinavian Journal of Medicine \& Science in Sports, 21(1), 79-84. https://doi:10.1111/j.1600-0838.2009.01024.x.

[42] Lees, A., \& Nolan, L. (2002). Three-dimensional kinematic analysis of the instep kick under speed and accuracy conditions. In: W. Spinks, T. Reilly, \& A. Murphy (Eds.), Science and Football IV (pp.16-21). 
London: Routledge.

[43] Beilock, S.L, Carr, T. H, MacMahon, C., \& Starkes, J.L. (2002). When paying attention becomes counterproductive: Impact of divided versus skill-focused attention on novice and experienced performance of sensorimotor skills. Journal of Experimental Psychology, 8(1), 6-16. https://doi.1037//1076-898X.8.1.6.

[44] Gabbett, T. J., \& Abernethy, B. (2013). Expert-novice differences in the anticipatory skill of rugby league players. Sport, Exercise, and Performance Psychology, 2(2), 138-155. https://doi.org/10.1037/a0031221.

[45] Huang, H. J., \& Mercer, V. S. (2001). Dual -task methodology: applications in studies of cognitive and motor performance in adults and children. Pediatric Physical Therapy, 13, 133-140.

[46] Ford, P., Hodges, N. J., Huys, R., \& Williams, A. M. The role of external action-effects in the execution of a soccer kick: A comparison across skill level. Motor Control. 2006; 10:386-

404. https://doi:10.1123/mcj.10.4.386.

[47] Lees, A., Asai, T., Andersen, T. B, Nunome, H., \& Sterzing, T. (2010). The biomechanics of kicking in soccer: A review. Journal of Sports Sciences, 28:805-817. https://doi:10.1080/02640414.2010.481305.

[48] Remaud, A., Boyas, S., Caron, G., \& Bilodeau, M. (2012). Attentional demands associated with postural control depend on task difficulty and visual condition.

Journal of Motor Behavior, 44, 329-341. https://doi:10.1080/00222895.2012.708680.

[49] Matsuda, S., Demura, S., \& Uchiyama, M. (2008). Centre of pressure sway characteristics during static one-legged stance of athletes from different sports. Journal of Sports Sciences, 26, 775-

779. https://doi:10.1080/02640410701824099.

[50] Paillard, T., \& Noé., F. (2006). Effect of expertise and visual contribution on postural control in soccer. Scandinavian Journal of Medicine \& Science in Sports, 16(5), 345-8. https://doi:10.1111/j.16000838.2005.00502.x.

[51] Hilt, P. M., Berret, B., Papaxanthis, C., Stapley, P. J., \& Pozzo, T. (2016). Evidence for subjective values guiding posture and movement coordination in a free-endpoint whole-body reaching task. Scientific Reports, 6(1). https://doi:10.1038/srep23868.

[52] Manolopoulos, E., Papadopoulos, C., \& Kellis, E. (2006). Effects of combined strength and kick coordination training on soccer kick biomechanics in amateur players. Scandinavian Journal of Medicine \& Science in Sports, 16, 102-110. https://doi:10.1111/j.1600-0838.2005.00447.x.

\section{Tables}

Table 1. Cartesian coordinates used in procedure of 3D calibration and their extreme XYZ reconstructed points analyzed in the accuracy test for the spatial calibration. 
Cartesian coordinates points

\begin{tabular}{|c|c|c|c|c|c|c|c|c|c|c|c|c|}
\hline & PTS & $x(\mathrm{~cm})$ & $r(\mathrm{~cm})$ & $z(\mathrm{~cm})$ & PTS & $x(\mathrm{~cm})$ & $\gamma(\mathrm{cm})$ & $z(\mathrm{~cm})$ & PTS & $x(\mathrm{~cm})$ & $\gamma(\mathrm{cm})$ & $z(\mathrm{~cm})$ \\
\hline & 1 & 0 & 0 & 20 & 20 & 0 & $\pi$ & 20 & 39 & 0 & 140 & 20 \\
\hline & 2 & 0 & 0 & 40 & 21 & 0 & 70 & 40 & 40 & 0 & 140 & 40 \\
\hline & 3 & 0 & 0 & 60 & 22 & 0 & 70 & 60 & 41 & 0 & 140 & 60 \\
\hline & 4 & 0 & 0 & 20 & 23 & 0 & 70 & 20 & 42 & 0 & 140 & 80 \\
\hline & 5 & 0 & 0 & 100 & 24 & 0 & 70 & 100 & 43 & 0 & 140 & 100 \\
\hline & 6 & 0 & 0 & 120 & 25 & 0 & 70 & 120 & 44 & 0 & 140 & 120 \\
\hline & 7 & 0 & 0 & 140 & 26 & 0 & 70 & 140 & as & 0 & 240 & 140 \\
\hline & 8 & 0 & 0 & 160 & 27 & 0 & 70 & 160 & 46 & 0 & 140 & 160 \\
\hline & 9 & 0 & 0 & 120 & 28 & 。 & 70 & 180 & 47 & 0 & 140 & 180 \\
\hline & 10 & 0 & 0 & 200 & 29 & 0 & 70 & 200 & 48 & 0 & 140 & 200 \\
\hline & 11 & 220 & 0 & 20 & 30 & 120 & 70 & 20 & 49 & 120 & 140 & 20 \\
\hline & 12 & 220 & o & 40 & 31 & 120 & 70 & 40 & so & 120 & 140 & 40 \\
\hline & 13 & 120 & 0 & 60 & 32 & 120 & 70 & $\infty$ & 51 & 120 & 140 & 60 \\
\hline & 14 & 120 & 0 & $s 0$ & 33 & 120 & 70 & 80 & 52 & 120 & 140 & 80 \\
\hline & 15 & 120 & 0 & 100 & 34 & 1220 & 70 & 100 & 53 & 120 & 140 & 100 \\
\hline & 17 & 120 & 0 & 140 & 36 & 120 & 70 & 140 & ss & 120 & 140 & 140 \\
\hline & 18 & 220 & 0 & 200 & 37 & 120 & 70 & 160 & 56 & 120 & 140 & 160 \\
\hline & 19 & 120 & 0 & 180 & 38 & 120 & 70 & 180 & 57 & 120 & 140 & 180 \\
\hline \multicolumn{13}{|c|}{$x y Z$ (Reconstructed points) } \\
\hline prs & 1 & 10 & 11 & 12 & 19 & 20 & 30 & 38 & 30 & 48 & 40 & 57 \\
\hline $\mathbf{x}$ & 0.9973 & 0,3552 & 0,5665 & 70,078 & 0.9423 & 70,368 & 69,467 & 70,395 & 139,508 & 139,34 & 139.99 & 138.74 \\
\hline $\mathbf{r}$ & -1.0324 & $-0,1299$ & 191,547 & 0,053 & 118,916 & $-2,784$ & 121,762 & 1220,902 & 0,3777 & 1,299 & 118,72 & 1220,4 \\
\hline$z$ & 21,2733 & 207,257 & 201,618 & 203,246 & 179,641 & 201,262 & 19,867 & 180,895 & 20,642 & 199,99 & 20,188 & 178,29 \\
\hline
\end{tabular}

Table 2. Mean and standard deviation of the actual values of $\mathrm{CoP}_{\text {predicted }}$ and $\mathrm{CoP}_{\text {measured }}$ in both directions (AP, ML) obtained through the distributed load test.

Point of loading application
$\mathrm{COP}_{\mathrm{AP}}(\mathrm{mm})$

$\operatorname{COP}_{\mathrm{ML}}(\mathrm{mm})$

\begin{tabular}{|lllll|}
\hline & predicted & measured & predicted & measured \\
\hline P1 & $18.76 \pm 0.36$ & $18.98 \pm 0.31$ & $10.02 \pm 0.50$ & $10.44 \pm 0.67$ \\
\hline P2 & $19.76 \pm 0.33$ & $20.03 \pm 0.75$ & $9.67 \pm 0.59$ & $10.01 \pm 0.47$ \\
\hline P3 & $19.82 \pm 0.23$ & $20.16 \pm 0.50$ & $9.80 \pm 0.61$ & $10.09 \pm 0.31$ \\
\hline P4 & $19.65 \pm 0.58$ & $19.90 \pm 0.40$ & $9.88 \pm 0.56$ & $10.27 \pm 0.87$ \\
\hline
\end{tabular}

Table 3. Summary of analysis of variance results for kicking performance (kicking time and foot acceleration) for the backswing and shooting phases. 


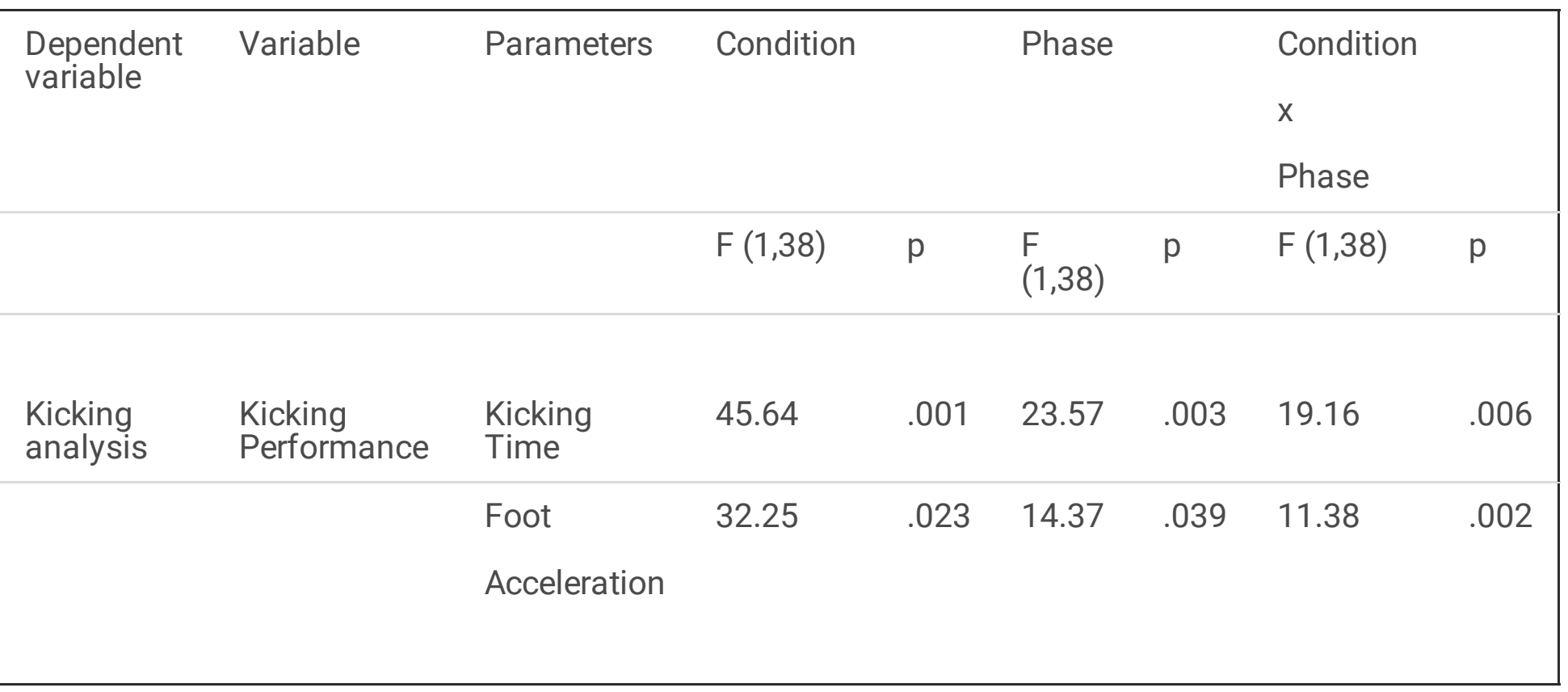

Table 4. Summary of analysis of variance results for CoP and CoM displacements (mean amplitude and speed) for the backswing and shooting phases.

\begin{tabular}{|c|c|c|c|c|c|c|c|c|}
\hline \multirow{4}{*}{$\begin{array}{l}\text { Dependent } \\
\text { variable }\end{array}$} & \multirow{4}{*}{$\begin{array}{l}\text { Variable } \\
\left({ }^{*}\right)\end{array}$} & \multirow[t]{4}{*}{ Parameters } & \multicolumn{2}{|l|}{ Condition } & \multicolumn{2}{|l|}{ Phase } & \multirow{3}{*}{\multicolumn{2}{|c|}{$\begin{array}{l}\text { Condition } \\
\mathrm{x} \\
\text { Phase }\end{array}$}} \\
\hline & & & & & & & & \\
\hline & & & & & & & & \\
\hline & & & $F(1,38)$ & $\mathrm{p}$ & $\begin{array}{l}\mathrm{F} \\
(1,38)\end{array}$ & $p$ & $F(1,38)$ & $p$ \\
\hline & & $\begin{array}{l}\text { Mean CoP } \\
\text { amplitude }\end{array}$ & 5.62 & .032 & 2.23 & .069 & 0.69 & .053 \\
\hline \multirow[t]{5}{*}{$\begin{array}{l}\text { CoP and } \\
\text { CoM } \\
\text { analysis }\end{array}$} & $\begin{array}{l}\text { CoP and CoM } \\
\text { displacements } \\
\text { in the AP axis }\end{array}$ & $\begin{array}{l}\text { Mean CoP } \\
\text { speed }\end{array}$ & 10.62 & .039 & 0.78 & .092 & 2.37 & .124 \\
\hline & & $\begin{array}{l}\text { Mean CoM } \\
\text { amplitude }\end{array}$ & & & & & & \\
\hline & & & 9.47 & .002 & 1.98 & .134 & 2.09 & .639 \\
\hline & & $\begin{array}{l}\text { Mean CoM } \\
\text { speed }\end{array}$ & & & & & & \\
\hline & & & 10.53 & .001 & 0.64 & .074 & 1.37 & .981 \\
\hline
\end{tabular}


* In the ML axis, no significant effect was observed for CoP and CoM displacement analysis.

\section{Figures}

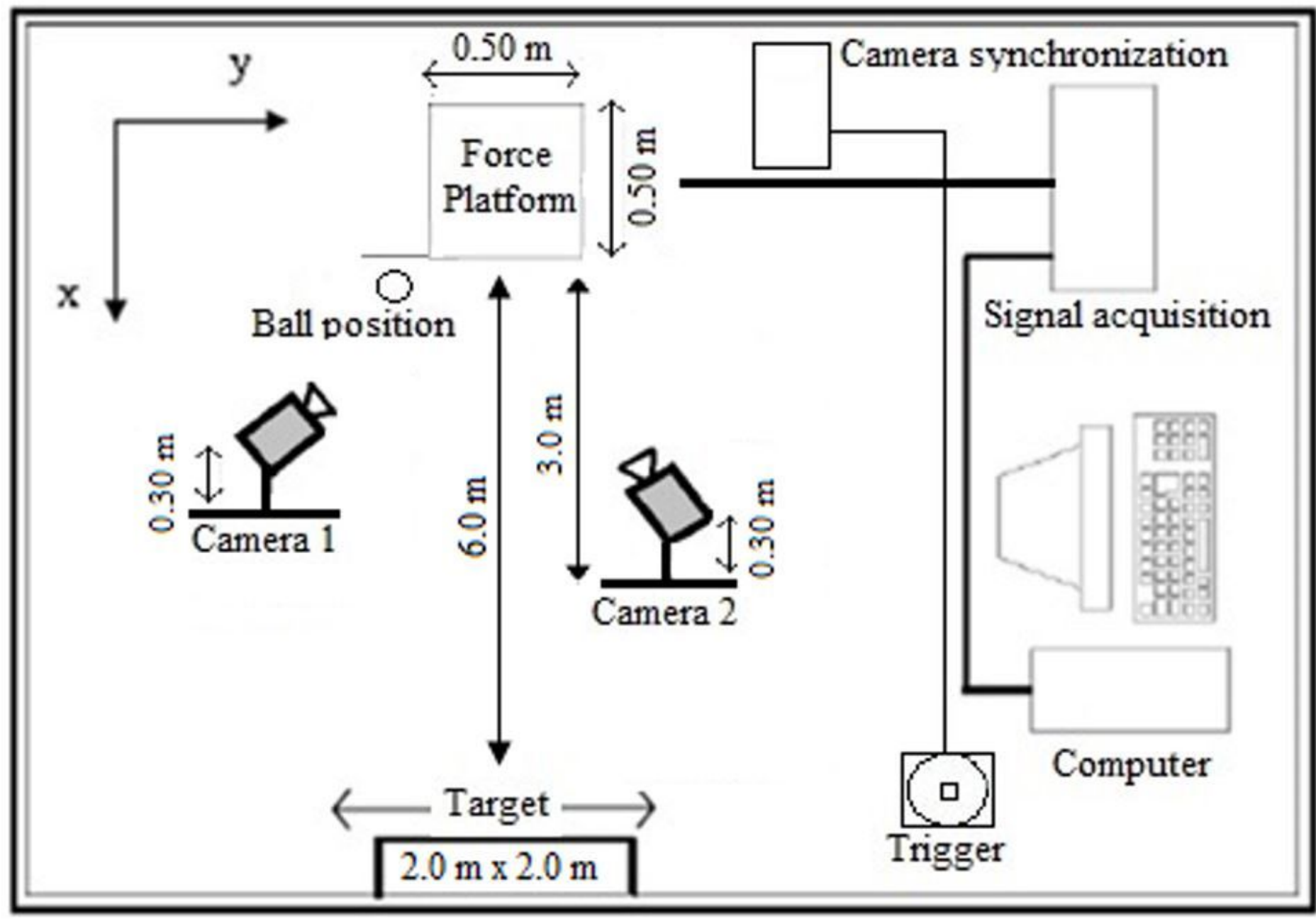

Figure 1

Experimental design developed for the biomechanical analysis of the soccer kick. 


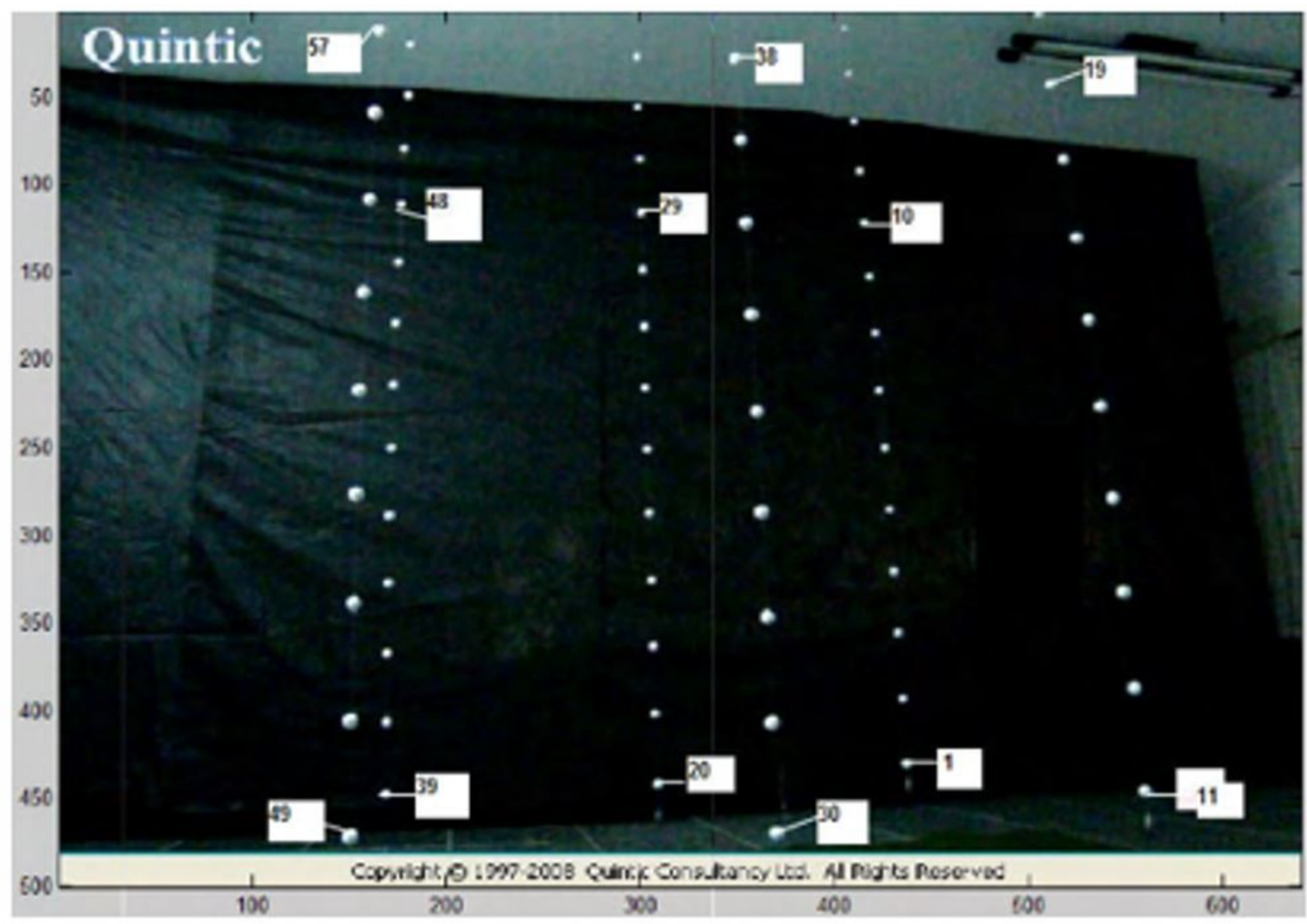

Figure 2

Marking sequence for 3D calibration (Quintic Player®). 
(a)

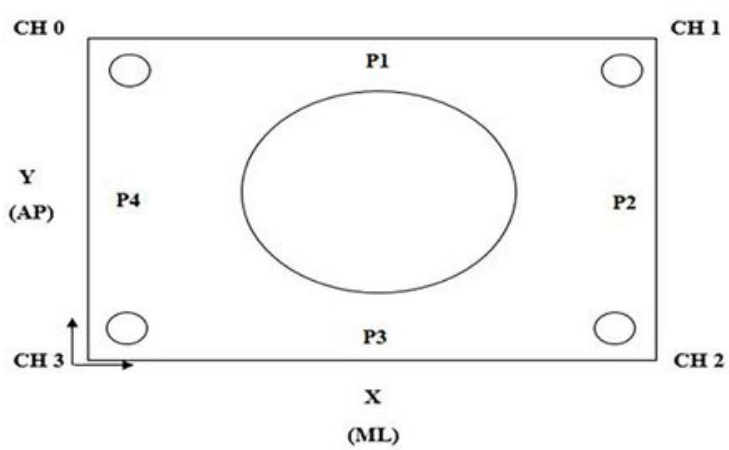

(b)

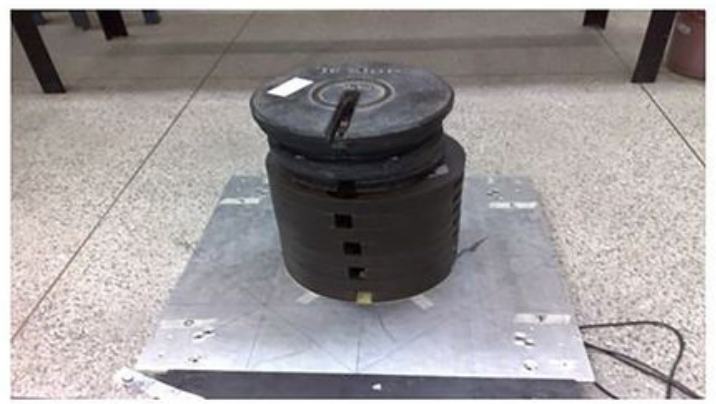

(c)

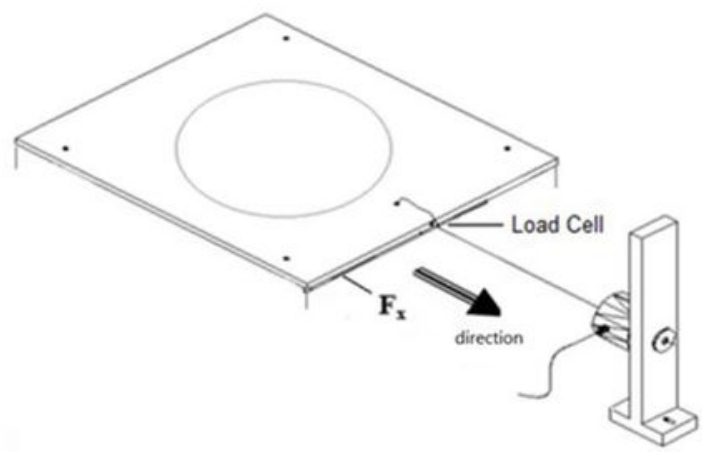

Figure 3

(a) Static calibration with load deposited at the center of platform; (b) The calibration procedure with four distinct points (P1, P2, P3, P4) placed $100 \mathrm{~mm}$ away from the center of the platform; (c) Schematic view of the horizontal platform calibration design. 

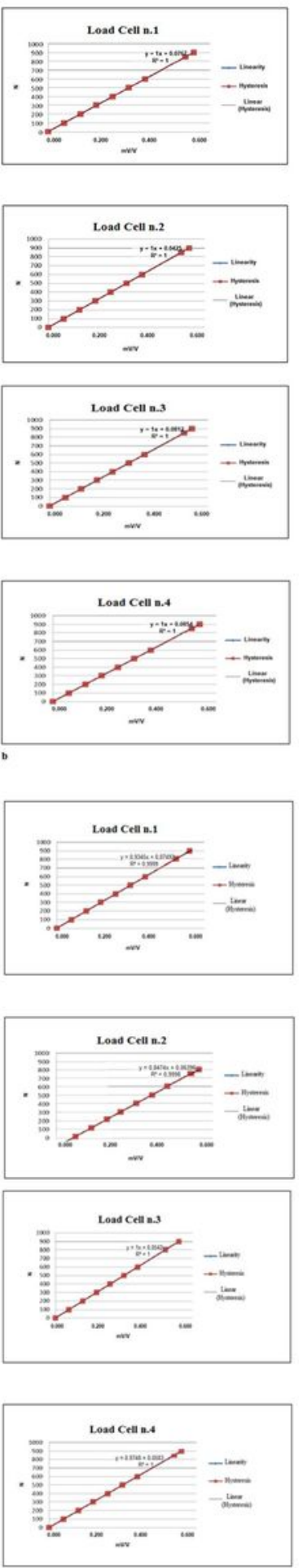

Figure 4

(a) Vertical and (b) Horizontal calibration results of the force platform, consisted of loading stages (0 to $900 \mathrm{~N})$ for each load cell separately.

\section{Supplementary Files}


This is a list of supplementary files associated with this preprint. Click to download.

- SUPPLEMENTARYMATERIAL.docx 